Check for updates

Cite this: RSC Adv., 2019, 9, 31683

Received 30th July 2019

Accepted 5th September 2019

DOI: 10.1039/c9ra05903b

rsc.li/rsc-advances

\section{Mesoporous $\mathrm{PbO}$ nanoparticle-catalyzed synthesis of arylbenzodioxy xanthenedione scaffolds under solvent-free conditions in a ball mill $\dagger$}

\author{
Trimurti L. Lambat, (D) *a Ratiram G. Chaudhary, (DD ${ }^{\mathrm{b}}$ Ahmed A. Abdala, ${ }^{\mathrm{c}}$ \\ Raghvendra Kumar Mishra, ${ }^{d}$ Sami H. Mahmood ${ }^{\star e}$ and Subhash Banerjee ${ }^{* f}$
}

A protocol for the efficient synthesis of arylbenzodioxy xanthenedione scaffolds was developed via a onepot multi-component reaction of aromatic aldehydes, 2-hydroxy-1,4-naphthoquinone, and 3,4methylenedioxy phenol using mesoporous $\mathrm{PbO}$ nanoparticles (NPs) as a catalyst under ball milling conditions. The synthesis protocol offers outstanding advantages, including short reaction time (60 min), excellent yields of the products (92-97\%), solvent-free conditions, use of mild and reusable PbO NPs as a catalyst, simple purification of the products by recrystallization, and finally, the use of a green process of dry ball milling.
Recently, the ball milling technique has received great attention as an environmentally benign strategy in the context of green organic synthesis. ${ }^{1 a}$ The process of "ball milling" has been developed by adding mechanical grinding to the mixer or shaker mills. The ball milling generates a mechanochemical energy, which promotes the rupture and formation of the chemical bonds in organic transformations. ${ }^{1 b}$ Subsequently, detailed literature ${ }^{1 c}$ and books on this novel matter have been published. ${ }^{2 a, b}$ Several typical examples include carbon-carbon and carbon-heteroatom bond formation, ${ }^{2 c}$ organocatalytic reactions, ${ }^{2 d}$ oxidation by using solid oxidants, ${ }^{2 e}$ dehydrogenative coupling, asymmetric, and peptide or polymeric material synthesis, which have been reported under ball milling conditions. $^{2 e}$ Hence, the organic reactions using ball milling activation carried out under neat reaction environments, exhibit major advantages, ${ }^{2 f}$ including short reaction time, lower energy consumption, quantitatively high yields and superior safety with the prospective for more improvement than the additional solvent-free conditions and clear-cut work-up. ${ }^{3-5}$

On the other hand, the organic transformations using metal and metal oxide nanoparticles ${ }^{6}$ are attracting enormous interest

${ }^{a}$ Department of Chemistry, Manoharbhai Patel College of Arts, Commerce \& Science, Deori, Gondia 441901, Maharashtra, India. E-mail: lambatges@gmail.com; Tel: $+917972047470$

${ }^{b}$ Post Graduate Department of Chemistry, S. K. Porwal College, Kamptee 441001, India ${ }^{c}$ Chemical Engineering Programme, Texas A \& M University at Qatar, POB 23784, Doha, Qatar

${ }^{d} I M E D A$ Materials, Technogetafe, Calle Eric Kandel, 2, 28906 Getafe, Madrid, Spain ${ }^{e}$ Department of Physics, The University of Jordan, Amman 11942, Jordan

${ }^{f}$ Department of Chemistry, Guru Ghasidas Vishwavidyalaya, Bilaspur, 495009, Chhattisgarh, India. E-mail: ocsb2006@gmail.com

$\dagger$ Electronic supplementary information (ESI) available. See DOI: $10.1039 / \mathrm{c} 9 \mathrm{ra05903b}$ due to the unique and interesting properties of the NPs. ${ }^{7,8,9 a}$ Particularly, $\mathrm{PbO} \mathrm{NPs}^{9 b}$ provide higher selectivity in some organic reactions $^{9 c}$ and find applications in various organic reactions, like Paal-Knorr reaction, ${ }^{\mathbf{1 0}}$ synthesis of diethyl carbonate, ${ }^{\mathbf{1 1}}$ phthalazinediones, ${ }^{\mathbf{1 2}}$ disproportionation of methyl phenyl carbonate to synthesize diphenyl carbonate, ${ }^{\mathbf{1 3}}$ the capping agent in organic synthesis, and selective conversion of methanol to propylene. ${ }^{\mathbf{1 4}}$ In addition, the PbO NPs are also used in many industrial materials. ${ }^{15,16}$

However, till date, PbO NPs have not been explored in MCRs leading to biologically important scaffolds. Among others, the xanthene scaffolds ${ }^{\mathbf{1 7}}$ are one of the important heterocyclic compounds $^{\mathbf{1 8}}$ and are extensively used as dyes, fluorescent ingredients for visual imaging of the bio-molecules, and in optical device technology because of their valuable chemical properties. $^{19}$ The xanthene molecules have conjointly been expressed for their antibacterial activity, ${ }^{20}$ photodynamic medical care, anti-inflammatory drug impact, and antiviral activity. Because of their various applications, the synthesis of these compounds has received a great deal of attention. ${ }^{21}$ Similarly, vitamin $\mathrm{K}$ nucleus ${ }^{22,23}$ shows a broad spectrum of biological properties, like anti-inflammatory, antiviral, antiproliferative, antifungal, antibiotic, and antipyretic. ${ }^{24 a}$ As a consequence, a variety of strategies ${ }^{24 b}$ have been demonstrated in the literature for the synthesis of xanthenes and their keto derivatives, like rhodomyrtosone- $\mathrm{B},{ }^{25 a}$ rhodomyrtosone$\mathrm{I}^{25 b}$ and BF-6 ${ }^{25 c}$ as well as their connected bioactive moieties. Few biologically active xanthene scaffolds are shown in (Fig. 1).

Due to the significance of these compounds, the synthesis of xanthenes and their keto derivatives using green protocols is highly desirable. Reported studies reveal that these scaffolds are synthesized by three-component condensations using $p$-TSA ${ }^{26}$ 

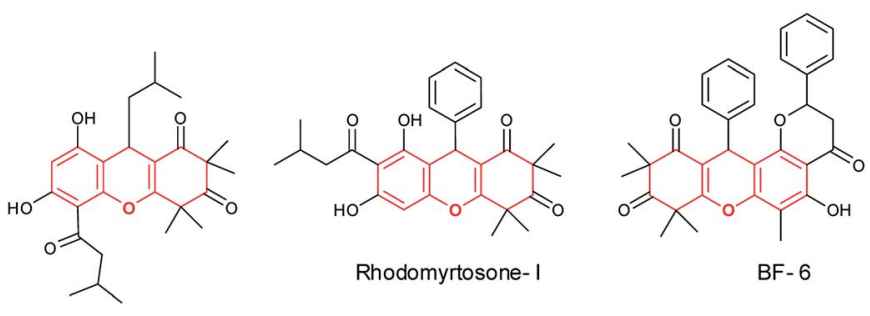

Rhodomyrtosone- B

Fig. 1 Some biologically important xanthenes and their keto derivatives.

and scolecite ${ }^{27}$ as catalysts. However, these methods suffer from the use of toxic acidic catalysts like $p$-TSA, long reaction times ( 3 h), harsh refluxing ${ }^{26}$ or microwave reaction conditions, ${ }^{27}$ and tedious work-up procedures. The previously reported methods for the synthesis of xanthenediones are shown in Scheme 1.

Herein, we report an economical and facile multicomponent protocol, using ball milling, for the synthesis of 7-aryl-6H-benzo $[H][1,3]$ dioxolo[4,5- $b]$ xanthene-5,6(7H)-dione using PbO NPs as a heterogeneous catalyst (Scheme 2). The PbO NPs are noncorrosive, inexpensive, and easily accessible.

In our protocol, ${ }^{28}$ the PbO NPs were initially prepared by mixing sodium dodecyl sulphate $(2.5 \mathrm{mmol})$ and sodium hydroxide $(10 \mathrm{~mL}, 0.1 \mathrm{~N})$ with an aqueous methanolic solution of lead nitrate $(2 \mathrm{mmol})$ under magnetic stirring at $30{ }^{\circ} \mathrm{C}$ by continuing the reaction for $2 \mathrm{~h}$. Then, the obtained white polycrystalline product was filtered, washed with $\mathrm{H}_{2} \mathrm{O}$, and dried at $120^{\circ} \mathrm{C}$, followed by calcination at $650{ }^{\circ} \mathrm{C}$ for $2 \mathrm{~h}$. During this step, the white PbO NPs turned pale yellow in colour. Eventually, the synthesized $\mathrm{PbO}$ was then characterized by spectroscopic and analytical techniques.

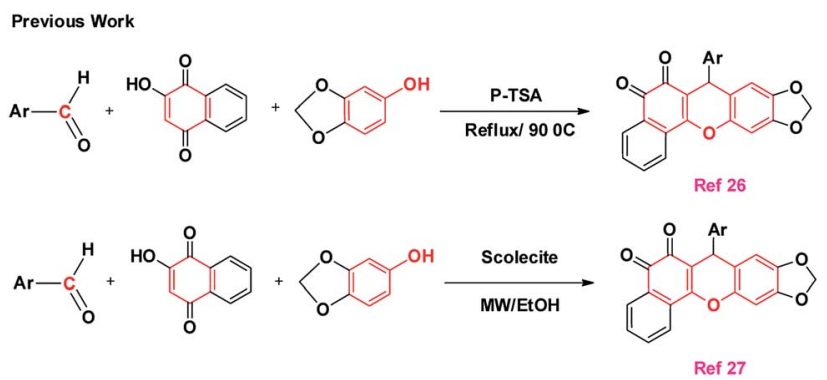

Scheme 1 Previous protocol for the synthesis of xanthenedione derivatives
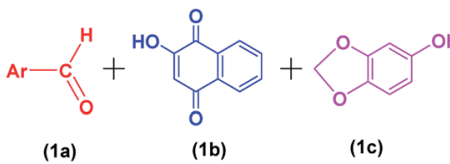

(1c)

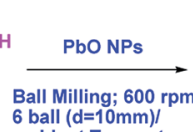
6 ball $(\mathrm{d}=10 \mathrm{~mm}) /$ ambient Temprature

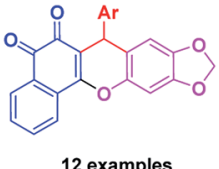

(2a-I)

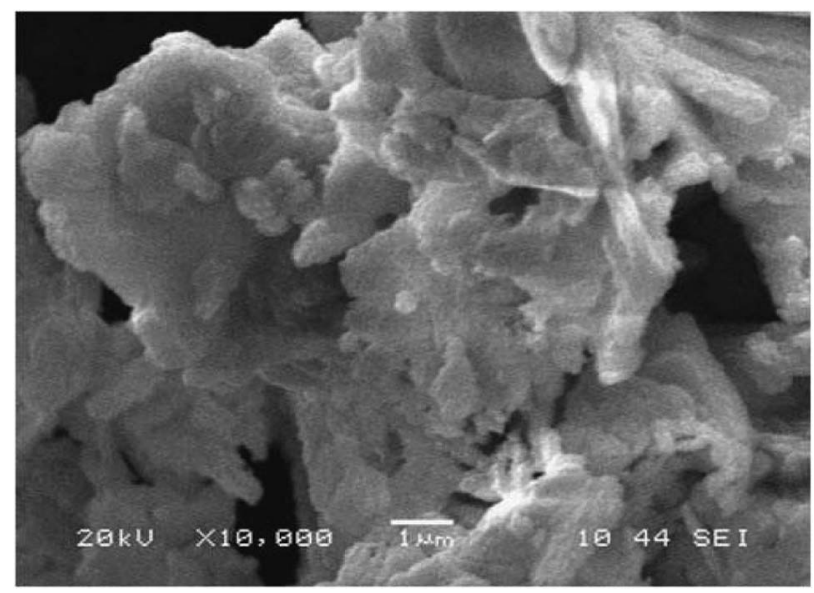

Fig. 3 The SEM image of PbO NPs.

Scheme 2 General reaction scheme of $\mathrm{PbO}$ NP-catalyzed synthesis of the xanthenedione scaffolds under ball milling conditions. 


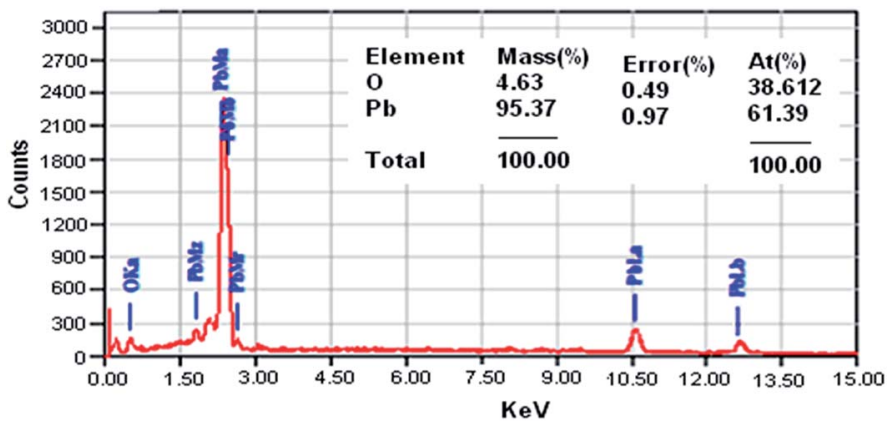

Fig. 4 The EDAX spectrum of crystalline PbO NPs.

TEM micrograph further confirmed the synthesis of PbO NPs, as the selected area diffraction pattern associated with such spots reveals the occurrence of the PbO NPs in total agreement with the X-ray diffraction data (Fig. 6). The average size of the $\mathrm{PbO}$ nanocrystals by TEM was approximated to be around $20 \mathrm{~nm}$.

The Fourier transform infrared (FT-IR) spectrum (ESI, S6 $\dagger$ ) of the PbO NPs displayed peaks at 575, 641, and $848 \mathrm{~cm}^{-1}$, which corresponds to the $\mathrm{Pb}-\mathrm{O}$ vibrations. Furthermore, the absorption band at $\sim 3315 \mathrm{~cm}^{-1}$ was due to the presence of the hydroxyl group $(-\mathrm{OH})$ in the NPs.

The $\mathrm{N}_{2}$ adsorption-desorption isotherms of the $\mathrm{PbO}$ nanoparticles shown in Fig. 7 was consistent with type IV adsorption-desorption isotherms with $\mathrm{H} 1$ hysteresis corresponding to the cylindrical mesoporous structure. Moreover, the surface area, pore-volume, and $\mathrm{BJH}$ pore diameter were found to be 32.0 $\mathrm{m}^{2} \mathrm{~g}^{-1}, 0.023 \mathrm{~cm}^{3} \mathrm{~g}^{-1}$, and $30.9 \AA$, respectively.

The catalytic activity of the synthesized PbO NPs was tested in a one-pot multicomponent synthesis of arylbenzodioxoloyl xanthenedione derivative under ball milling condition

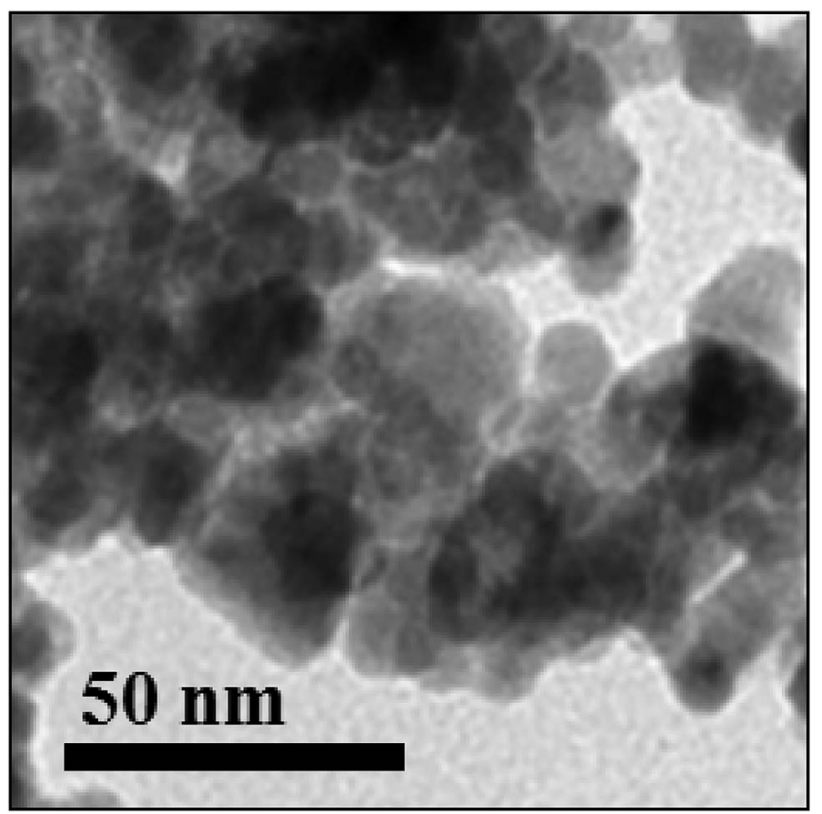

Fig. 5 The TEM image of nanocrystalline PbO NPs.

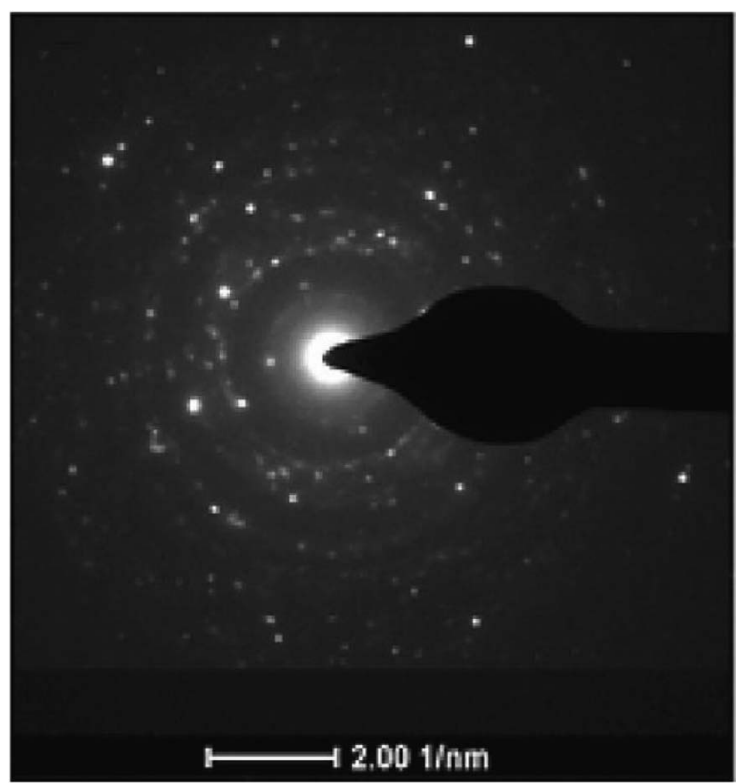

Fig. 6 The SAED image of nanocrystalline PbO NPs.

according to the reaction scheme 2a, with 3,4-dimethoxybenzaldehyde (166.2 mg, $1.0 \mathrm{mmol}$ ), 3,4-methylenedioxyphenol (138.0 mg, $1.0 \mathrm{mmol})$, and 2-hydroxy-1,4-

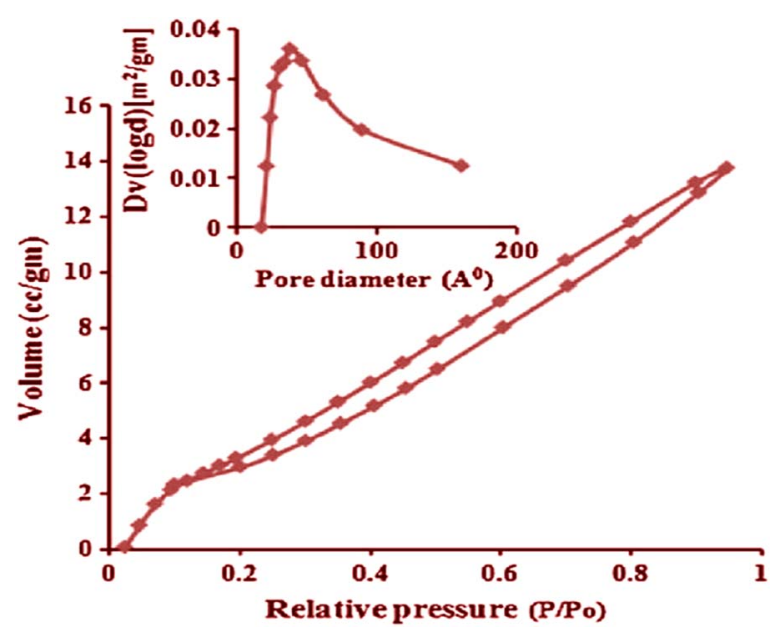

Fig. 7 BET surface area and pore size of nanocrystalline $\mathrm{PbO}$ catalyst. 
Table 1 The optimization of reaction conditions for the synthesis of xanthenedione derivative $2 a$

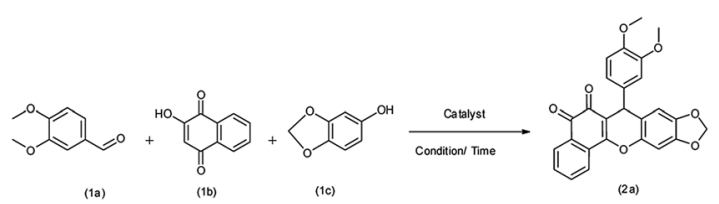

\begin{tabular}{|c|c|c|c|c|c|}
\hline Entry & Conditions & Rotation (rpm) & Catalyst (mol\%) & Time (min) & Yield $(\%)^{a}$ \\
\hline 1 & Ball milling & 400 & 00 & 50 & 21 \\
\hline 2 & Ball milling & 400 & 10 & 50 & 48 \\
\hline 4 & Ball milling & 400 & 20 & 70 & 59 \\
\hline 5 & Ball milling & 500 & 10 & 50 & 62 \\
\hline 6 & Ball milling & 500 & 15 & 50 & 65 \\
\hline 9 & Ball milling & 600 & 15 & 50 & 77 \\
\hline 10 & Ball milling & 600 & 20 & 60 & 82 \\
\hline 11 & Ball milling & 600 & 05 & 70 & 90 \\
\hline 12 & Ball milling & 600 & 10 & 50 & 91 \\
\hline 13 & Ball milling $^{b}$ & 600 & 15 & 60 & 97 \\
\hline 14 & Ball milling & 600 & 20 & 70 & 97 \\
\hline
\end{tabular}

${ }^{a}$ Isolated yield; model reaction: 3,4-dimethoxybenzaldehyde (166.2 mg, $1.0 \mathrm{mmol}$ ), 3,4-methylenedioxyphenol (138.1 mg, 1.0 mmol), 2-hydroxy-1,4naphthoquinone $(174.1 \mathrm{mg}, 1.0 \mathrm{mmol})$ under ball milling. ${ }^{b}$ Optimized reaction conditions. ${ }^{c}$ The reaction was performed under stirring condition in a RB flask.

naphthoquinone $(174.0 \mathrm{mg}, 1.0 \mathrm{mmol})$ as reactants. The reaction conditions, the ball milling parameters (speed, time, and ball to solids ratio), and the $\mathrm{PbO}$ nanocatalyst amount were first optimized to produce the highest yield using experimental design as shown in Table 1 . The ball milling at 600 ( 6 balls) rpm for $60 \mathrm{~min}$ under solvent-free conditions was established as the

Table 2 Scope of the PbO NP-catalyzed synthesis of arylbenzodioxoloyl xanthenedione derivatives

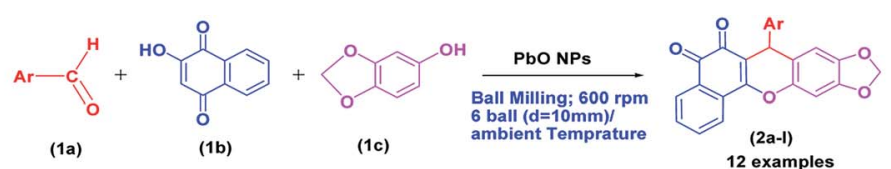

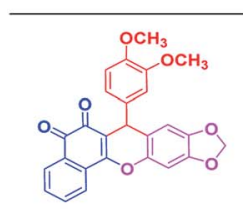

$2 \mathrm{a}, 97 \%$

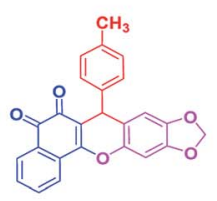

2f, $91 \%$

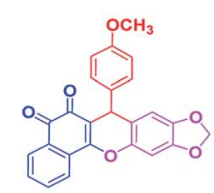

$2 b, 94 \%$<smiles>O=C1C(=O)c2ccccc2C(=O)C1=C1COc2cc3c(cc21)OCO3</smiles>

$2 \mathrm{~g}, 87 \%$

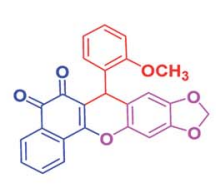

2c, $90 \%$

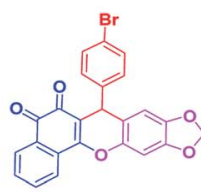

2h, $90 \%$

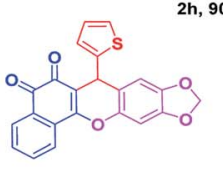

2k, $90 \%$

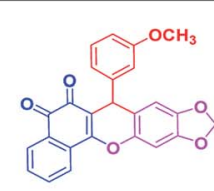

2d, $94 \%$<smiles>O=C1C(=O)c2ccccc2C2=C1C(c1ccc([N+](=O)[O-])cc1)c1cc3c(cc1O2)OCO3</smiles>

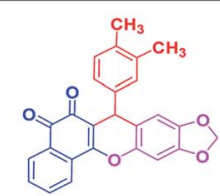

$2 e, 89 \%$<smiles></smiles>

2j, $91 \%$ 2i, $86 \%$

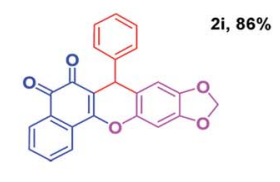

21, $87 \%$ 


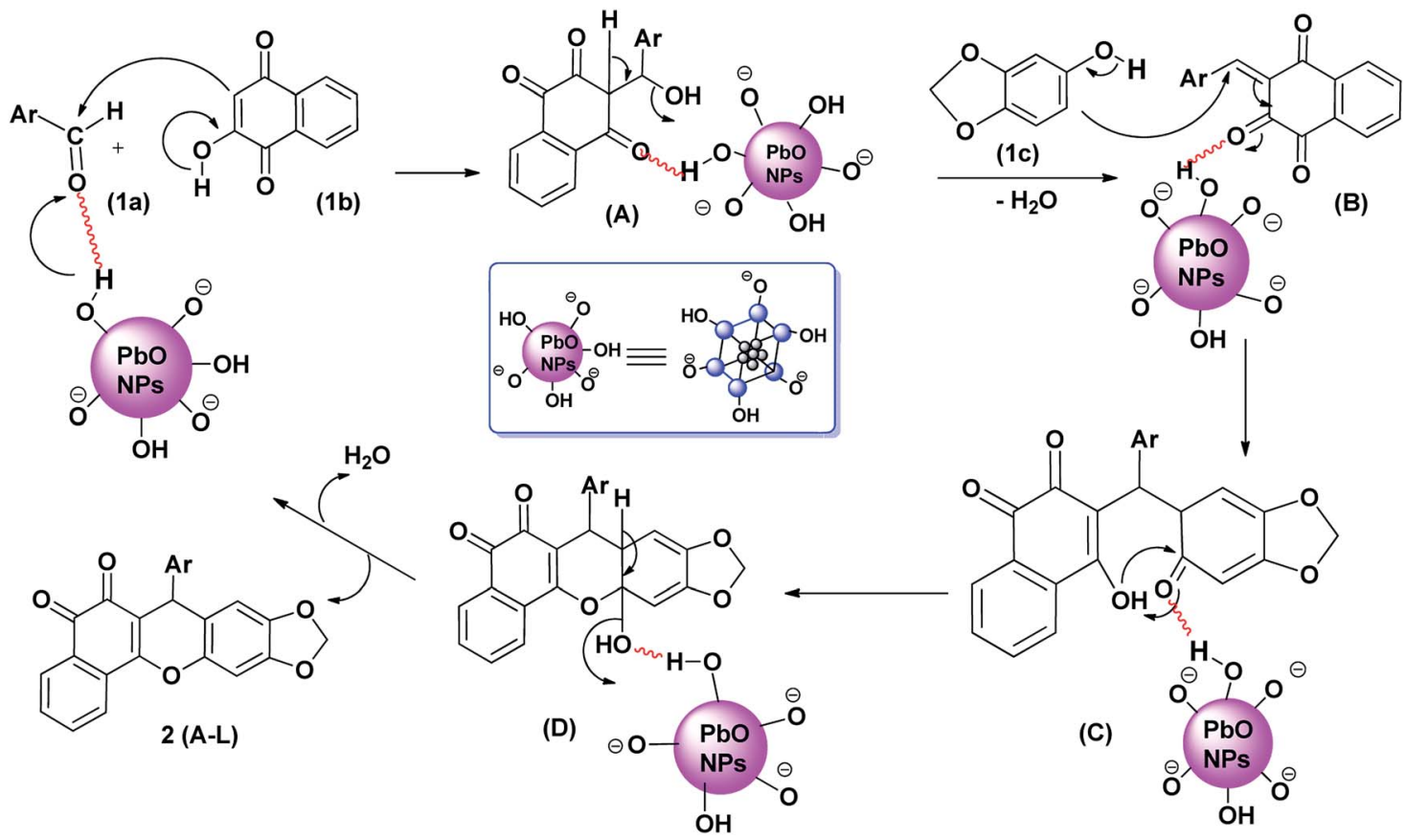

Scheme 3 Plausible mechanism of PbO NP-catalyzed synthesis of arylbenzodioxoloyl xanthenedione (2a).

optimized reaction conditions (entry 13, Table 1). Further, to understand the effect of ball milling, we also performed the model reaction in an RB flask under normal conditions without ball milling (entry 15, Table 1). However, the reaction did not initiate under these conditions, which demonstrated that ball milling provides sufficient energy to the reaction leading to the formation of the product.

Next, by utilizing the general experimental procedure (ESI $\dagger$ for detail experimental procedure; S2) and the aforementioned optimized conditions (Table 1), we examined the range of conditions for the synthesis of arylbenzodioxoloyl xanthenedione scaffolds. Moreover, we demonstrated that using $\mathrm{PbO}$ NPs as a catalyst leads to outstanding yield (92-97\%) of 7-aryl$6 \mathrm{H}$-benzo[ $h][1,3]$ dioxolo $[4,5-b]$ xanthene-5.6(7H)-dione (2a-1) by the condensation of a variety of substituted aromatic aldehydes, 2-hydroxy-1,4-naphthoquinone, and 3,4-methylenedioxyphenol under the optimized conditions.

With the optimal conditions and using general experimental procedure, ${ }^{29}$ we also investigated the possible scopes of the reactants as revealed in Table 2. All these arylbenzodioxoloyl xanthenediones are well-known scaffolds and were simply recognized by the assessment of their spectroscopic information with earlier reports. ${ }^{26}$ These data are available in S4 (see ESI $\dagger$ for the spectroscopic data). The aromatic aldehydes comprising both electron-withdrawing (e.g., nitro group) and electron-donating (e.g., - $\mathrm{OMe},-\mathrm{OH},-\mathrm{Cl},-\mathrm{Me}$, and $-\mathrm{Br}$ ) groups participated proficiently in the reaction without including any electronic effects. The aromatic aldehyde with electrondonating groups (e.g., -OMe, $-\mathrm{OH},-\mathrm{Cl},-\mathrm{Me}$, and $-\mathrm{Br}$ ) increased the product yield, while in the case of aryl aldehyde

Table 3 A comparative study of present and previous methods

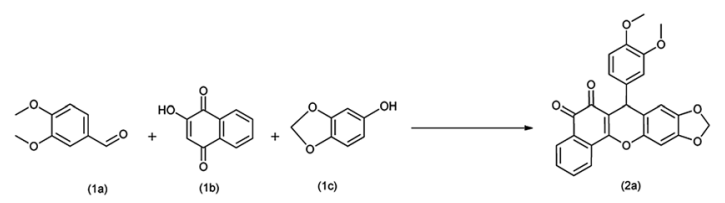

\begin{tabular}{|c|c|c|c|c|c|}
\hline Sr. no. & Catalyst & Reaction conditions & Yield (\%) & Time (min) & Reusable? \\
\hline 1 & $p-$ TSA $^{26}$ & $\mathrm{EtOH} / 90-120^{\circ} \mathrm{C}$ & $85-90$ & 180 & No \\
\hline 2 & Scolecites ${ }^{27}$ & $\mathrm{EtOH} / 80^{\circ} \mathrm{C}$ & $90-92$ & 4-15 MW & Yes up to 3 cycles \\
\hline
\end{tabular}

${ }^{a}$ Present work. 
having an electron-withdrawing group (e.g., $-\mathrm{NO}_{2}$ ), both the product yield as well as the reaction rate decreased. These findings are depicted in Table 2 . All the prepared xanthenedione derivatives were purified via recrystallization from hot ethanol and extracted as solids, and thus, any column chromatography step was not required in the present protocol. The compounds were then confirmed by measuring their melting points (MP), followed by spectroscopic analysis using ${ }^{1} \mathrm{H}$ and ${ }^{13} \mathrm{C}$ NMR spectra provided in S5, ESI. $\dagger$

Following a previously reported mechanism, ${ }^{26}$ a possible mechanism for the synthesis of arylbenzodioxoloyl xanthenedione derivative under ball milling at $600 \mathrm{rpm}$ for $60 \mathrm{~min}$ is shown in Scheme 3. It is speculated that in the first step, the surface of the PbO NPs having free -O-H groups facilitated the carbon-carbon bond formation by activating aromatic aldehyde $\mathbf{1 a}$ to react with 2-hydroxy-1,4-naphthoquinone $\mathbf{1 b}$ leading to the intermediate $\mathbf{B}$, which further undergoes dehydration, followed by the addition of 3,4-methylenedioxyphenol 1c, which upon cyclization leads to the formation of the product 2 a with the recovery of the catalyst, PbO NPs.

Further, to signify the advantages of the current methodology, a comparative study of known methods is provided in Table 3, which clarifies the effectiveness of the PbO NP catalyst over known $p$-TSA and scolecites in terms of product yields, reaction times, and catalyst recyclability. A comparative study of the present method to that of the reported methods for the synthesis of arylbenzodioxoloyl xanthenediones is shown in Table 3.

Next, we investigated the reusability of the $\mathrm{PbO}$ nanocatalyst for the synthesis of 7-(3,4-dimethoxyphenyl)-6H-benzo[ $H][1,3]$ dioxolo $[4,5-b]$ xanthene-5,6(7H)-dione $(2 \mathrm{a})$ as a model reaction. After the reaction, PbO NPs were separated from the reaction mixture by centrifugation, washed consecutively with aqueous ethanol, dried, and reused for the next run. As shown in Fig. 8, the reaction yield was reduced by only $12 \%$ after eight consecutive runs. This slight decrease in the yield was observed due to the loss of PbO NPs ( $\sim 10 \mathrm{wt} \%)$ during the recycling process.

The fate of the recycled PbO NPs was analyzed by performing SEM and TEM studies after the $8^{\text {th }}$ run, and considerable agglomeration of NPs was observed. However, interestingly the

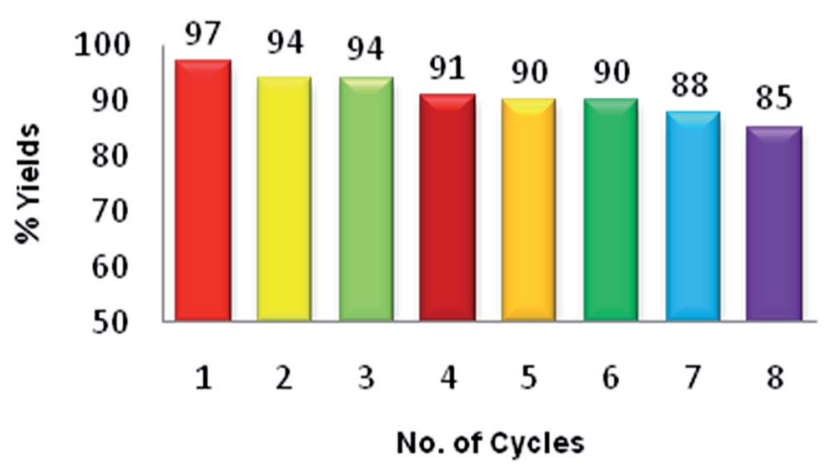

Fig. 8 Reusability of PbO NPs for the synthesis of 7-(3,4-dimethoxyphenyl)-6H-benzo[H][1,3]dioxolo[4,5-b]xanthenes-5,6 (7H)-dione as a model reaction.
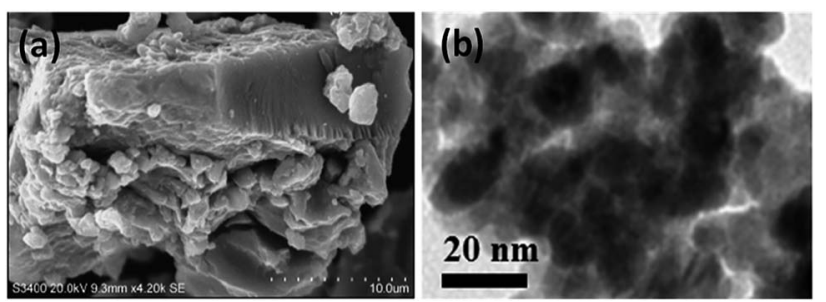

Fig. 9 (a) SEM and (b) TEM images of the recycled PbO NPs after $8^{\text {th }}$ run.

particle size of the NPs reduced to $\sim 15 \mathrm{~nm}$ compared to fresh PbO NPs during the ball milling process (Fig. 9).

In conclusion, we demonstrated a facile and efficient method for the synthesis of 7-aryl-6H-benzo[ $H][1,3]$ dioxolo[4,5$b]$ xanthene-5,6(7H)-dione using PbO NPs as a catalyst. The entire synthesis process was very clean and provided very high yields (86-97\%) of xanthenedione derivatives (2a-1) via mild ball milling. Moreover, the present protocol has demonstrated significant development in terms of higher isolated yields, faster rate of reaction $(1 \mathrm{~h})$, and most importantly, it is environment-friendly. Moreover, the use of solvent-free ball milling conditions allows simple isolation and purification of the products, with no column chromatography, as well as the mild PbO NPs as a reusable catalyst made the current synthetic method more suitable and environmentally benign in nature.

\section{Conflicts of interest}

There are no conflicts to declare.

\section{Acknowledgements}

Dr T. L. Lambat thankfully acknowledges the research grant awarded from DST, New Delhi for the INSPIRE Fellowship [IF120418]. We are also grateful to Dr S. S. Deo \& Dr F. S. Inam for their constant encouragement.

\section{References}

1 (a) N. Mukherjee, S. Ahammed, S. Bhadra and B. C. Ranu, Green Chem., 2013, 15, 389; (b) J. Yu, G. Peng, Z. Jiang, Z. Hong and W. Su, Eur. J. Org. Chem., 2016, 32, 5340; (c) S. Zhao, Y. Li, C. Liu and Y. Zhao, Tetrahedron Lett., 2018, 59, 317.

2 (a) R. Thorwirth and A. Stolle, Synlett, 2011, 15, 2200; (b) E. Tullberg, D. Peters and T. Frejd, J. Organomet. Chem., 2004, 689, 3778; (c) T. Szuppa, A. Stolle, B. Ondruschka and W. Hopf, Green Chem., 2010, 12, 1288; (d) R. Thorwirth, F. Bernhardt, A. Stolle, B. Ondruschka and J. Asghari, Chem.-Eur. J., 2010, 16, 13236; (e) T. Chatterjee, D. Saha and B. C. Ranu, Tetrahedron Lett., 2012, 53, 4142; (f) A. Stolle, T. Szuppa, S. E. S. Leonhardt and B. Ondruschka, Chem. Soc. Rev., 2011, 40, 2317.

3 S. L. James, C. J. Adams, C. Bolm, D. Braga, P. Collier, T. Friscic, F. Grepioni, K. D. M. Harris, G. Hyett, W. Jones, 
A. Krebs, J. Mack, L. Maini, A. G. Orpen, I. P. Parkin, W. C. Shearouse, J. W. Steed and D. C. Waddell, Chem. Soc. Rev., 2012, 41, 413.

4 B. Rodriguez, A. Bruckmann, T. Rantanen and C. Bolm, Adv. Synth. Catal., 2007, 349, 2213.

5 (a) R. Schimdt, R. Thorwirth, T. Szuppa, A. Stolle, B. Ondruschka and H. Hopf, Chem.-Eur. J., 2011, 17, 8129; (b) R. Thorwirth, A. Stolle and B. Ondruschka, Green Chem., 2010, 12, 985.

6 S. Stankic, S. Suman and F. H. J. Vidic, J. Nanobiotechnol., 2016, 14, 1-20.

7 B. Mirtamizdoust, B. Shaabani, et al., Z. Anorg. Allg. Chem., 2012, 638, 844.

8 T. Lambat, J. Chin. Adv. Mater. Soc., 2018, 6, 134-144.

9 (a) L. S. Gadekar, S. S. Katkar, S. R. Mane, B. R. Arbad and M. K. Lande, Bull. Korean Chem. Soc., 2009, 30, 11; (b) B. Gerard, J. Ryan, A. B. Beeler and J. A. Porco Jr., Tetrahedron, 2006, 62, 6405; (c) A. Marra, A. Vecchi, C. Chiappe, B. Melai and A. Dondoni, J. Org. Chem., 2008, 73, 2458.

10 S. K. Pashaa, V. S. V. Satyanarayana, A. Sivakumar, K. Chidambaram and L. John Kennedy, Chin. Chem. Lett., 2011, 22, 891.

11 H. An, X. Zhao, L. Guo, C. Jia, B. Yuan and Y. Wang, Appl. Catal., A, 2012, 433-434, 229.

12 R. Tayebee, B. Maleki and M. Sabeti, J. Iran. Chem. Soc., 2017, 14, 1179.

13 S. Wang, C. Li, Z. Xiao, T. Chen and G. Wang, J. Mol. Catal. A: Chem., 2016, 420, 26.

14 H. Zhang, Z. Ning, J. Shang, H. Liu, S. Han, W. Qu, Y. Jiang and Y. Guo, Microporous Mesoporous Mater., 2017, 248, 173.

15 D. Kumar, V. B. Reddy, S. Sharad, U. Dube and S. Kapur, Eur. J. Med. Chem., 2009, 44, 3805.

16 (a) T. Lambat, S. Deo, F. Inam, T. Deshmukh and A. Bhat, Karbala International Journal of Modern Science, 2016, 2, 63; (b) T. L. Lambat, S. S. Deo and T. B. Deshmukh, J. Chem. Pharm. Res., 2014, 6(4), 888; (c) T. L. Lambat and S. S. Deo, Der Pharm. Lett., 2014, 6(3), 218; (d) T. Lambat and S. Deo, J. Chin. Adv. Mater. Soc., 2016, 5(1), 20; (e) T. L. Lambat and S. S. Deo, J. Chin. Adv. Mater. Soc., 2017, 5(2), 65.

17 T. R. Mandlimath, B. Umamahesh and K. I. Sathiyanarayanan,J. Mol. Catal. A: Chem., 2014, 391, 198.

18 A. Saeed, G. Shabir and S. A. Shehzadi, J. Chin. Chem. Soc., 2016, 63, 181.

19 D. Castañeda-Antonio, A. Rivera, E. Islas-Rodríguez, R. Portillo-Reyes, J. Muñoz-Rojas, F. Hernández-Aldana and D. Martínez-Carrera, ARPN J. Agric. Biol. Sci., 2015, 10, 390393.

20 Ž. Lukšienè, Medicina, 2003, 29, 1137-1150.

21 (a) S. Banerjee and S. Santra, Tetrahedron Lett., 2009, 50, 2037; (b) S. Banerjee, J. Das, R. Alverez and S. Santra, New J. Chem., 2010, 34, 302; (c) S. Banerjee, V. Balasanthiran, R. Koodali and G. Sereda, Org. Biomol. Chem., 2010, 8, 4316; (d) S. Banerjee, A. Horn, H. Khatri and G. Sereda, Tetrahedron Lett., 2011, 52, 1878; (e) S. Banerjee and A. Saha, New J. Chem., 2013, 37, 4170; $(f)$ S. Banerjee, S. Payra, A. Saha and G. Sereda, Tetrahedron Lett., 2014, 55,
5515; $(g)$ A. Saha, S. Payra and S. Banerjee, Green Chem., 2015, 17, 2859; (h) S. Banerjee, New J. Chem., 2015, 39, 5350. 22 (a) A. Saha, S. Payra and S. Banerjee, RSC Adv., 2015, 5, 101664; (b) A. Saha, S. Payra, S. K. Verma, M. Mandal, S. Thareja and S. Banerjee, RSC Adv., 2015, 5, 100978; (c) S. Payra, A. Saha and S. Banerjee, RSC Adv., 2016, 6, 12402; (d) S. Payra, A. Saha, S. Guchhait and S. Banerjee, $R S C$ $A d v$., 2016, 6, 33462; (e) S. Payra, A. Saha and S. Banerjee, RSC Adv. , 2016, 6, 52495.

23 (a) A. Stolle, T. Szuppa, S. E. S. Leonhardt and B. Ondruschka, Chem. Soc. Rev., 2011, 40, 2317; (b) B. Rodriguez, A. Bruckmann, T. Rantanen and C. Bolm, Adv. Synth. Catal., 2007, 349, 2213.

24 (a) S. L. James, C. J. Adams, C. Bolm, D. Braga, P. Collier, T. Friscic, F. Grepioni, K. D. M. Harris, G. Hyett, W. Jones, A. Krebs, J. Mack, L. Maini, A. G. Orpen, I. P. Parkin, W. C. Shearouse, J. W. Steed and D. C. Waddell, Chem. Soc. Rev., 2012, 41, 413; (b) M. J. Climent, A. Corma and S. Iborra, Chem. Rev., 2011, 111, 1072.

25 (a) S. Limsuwan, E. N. Trip, T. R. Kouwen, S. Piersma, A. Hiranrat, W. Mahabusarakam, S. P. Voravuthikunchai, J. M. van Dijl and O. Kayser, Phytomedicine, 2009, 16, 645651; (b) A. Gervais, K. E. Lazarski and J. A. Porco, J. Org. Chem., 2015, 2, 9584-9591; (c) G. M. Ziarani, A. R. Badiei and M. Azizi, Sci. Iran., 2011, 18, 453-457.

26 K. Qian, Z. Fu, X. Cao, S. Li, T. Shen and Q. Song, Synth. Commun., 2017, 47, 37-43.

27 T. L. Lambat, Int. J. Appl. Biol. Pharm. Technol., 2017, 8, 1118.

28 General procedure for the preparation of PbO NPs: a combination of sodium dodecyl sulphate $(720 \mathrm{mg}, 2.5$ mmol) and sodium hydroxide $(10 \mathrm{~mL}, 0.1 \mathrm{~N})$ in distilled water was added to a magnetically stirred lead nitrate (662 $\mathrm{mg}, 2 \mathrm{mmol}$ ) solution in methanol $(10 \mathrm{~mL})$. The reaction combination was agitated for $2 \mathrm{~h}$ at $30{ }^{\circ} \mathrm{C}$. The whitish polycrystalline product was formed which was filtered, washed with distilled water $(3 \times 2 \mathrm{~mL})$, and dried at $120{ }^{\circ} \mathrm{C}$ for $2 \mathrm{~h}$. The white solid material was calcined at $650{ }^{\circ} \mathrm{C}$ for $2 \mathrm{~h}$. During this process, the white $\mathrm{PbO}$ turned pale yellow in colour. Eventually, the formation of $\mathrm{PbO}$ NPs was confirmed by various analytical techniques.

29 General Procedure for synthesis of xanthenedione derivatives using ball milling technique: Representative experimental procedure for the synthesis of 7-(3,4dimethoxyphenyl)-6H-benzo[ $h][1,3]$ dioxolo[4,5-b]xanthene5,6(7H)-dione (2A): a mixture of 3,4-dimethoxybenzaldehyde (166.2 mg, $1 \mathrm{mmol}$ ), 2-hydroxy-1,4-naphthoquinone (138.1 mg, $1 \mathrm{mmol}$ ), 3,4-methylenedioxyphenol (171.1 mg, $1.0 \mathrm{mmol}$ ), and PbO NPs (25 mg, $15 \mathrm{~mol} \%$ ) was taken in $25 \mathrm{~mL}$ stainless steel beaker and ball-milling was done at $600 \mathrm{rpm}$ with six balls $(d=10 \mathrm{~mm})$ for $60 \mathrm{~min}$. The ballmilling was carried out at inverted rotation directions, with the time interval of 10 minutes, having an interval break of $30 \mathrm{~s}$. Further, the reaction mixture was extracted by carrying out elution with ethanol $(5 \mathrm{~mL})$, followed by solvent evaporation to furnish the crude product (2a-1). The products were purified by recrystallization in ethanol. 
This methodology was applicable to all the reactions listed in Table 2. The remaining catalyst was washed with ethanol $(2 \mathrm{~mL})$, followed by acetone $(2 \mathrm{~mL})$, dried up under vacuum, and reused for the next run. Analytical dada for selected products: 7-(3,4-dimethoxyphenyl)-6 $\mathrm{H}$ benzo[ $h][1,3]$ dioxolo[4,5- $b]$ xanthene-5,6(7H)-dione $(\mathbf{2 a}):{ }^{1} \mathrm{H}$ NMR (DMSO-d $6,500 \mathrm{MHz}) \delta: 8.20(\mathrm{~d}, J=7.6 \mathrm{~Hz}, 1 \mathrm{H}), 8.10$ $(\mathrm{d}, J=7.8 \mathrm{~Hz}, 1 \mathrm{H}), 8.00(\mathrm{t}, J=7.6 \mathrm{~Hz}, 1 \mathrm{H}), 7.80(\mathrm{t}, J=$ $7.7 \mathrm{~Hz}, 1 \mathrm{H}), 7.25(\mathrm{~s}, 1 \mathrm{H}), 7.10(\mathrm{~s}, 1 \mathrm{H}), 6.85(\mathrm{~s}, 1 \mathrm{H}), 6.65(\mathrm{~d}$, $J=8.1 \mathrm{~Hz}, 1 \mathrm{H}), 6.80$ (d, $J=8.4 \mathrm{~Hz}, 1 \mathrm{H}), 6.15$ (s, 1H), 6.10 (s, 1H), $5.15(\mathrm{~s}, 1 \mathrm{H}), 3.72(\mathrm{~s}, 3 \mathrm{H}), 3.64(\mathrm{~s}, 3 \mathrm{H}) ;{ }^{13} \mathrm{C} \mathrm{NMR}$ (DMSO-d $\left.\mathrm{d}_{6}, 125 \mathrm{MHz}\right) \delta$ : 177.9, 175.6, 160.0, 155.0, 146.5, 147.5 , 146.7, 142.9, 140.6, 137.8, 135.0, 131.3, 130.2, 128.4,
124.3, 119.4, 115.0, 113.4, 111.0, 110.8, 106.8, 99.8, 98.5, 53.5, 53.5, 36.1; HRMS (ESI) calc. for $\mathrm{C}_{26} \mathrm{H}_{19} \mathrm{O}_{7}\left([\mathrm{M}+\mathrm{H}]^{+}\right)$: 443.1126. Found: 443.1133. 7-(4-methoxyphenyl)-6H-benzo $[h][1,3]$ dioxolo[4,5- $b]$ xanthene-5,6(7H)-dione (2b): ${ }^{1} \mathrm{H}$ NMR $\left(\right.$ DMSO-d $\left._{6}, 500 \mathrm{MHz}\right) \delta: 8.11$ (d, $\left.J=7.6 \mathrm{~Hz}, 1 \mathrm{H}\right), 7.99$ (dd, $J$ $=7.5,1.0 \mathrm{~Hz}, 1 \mathrm{H}), 7.88(\mathrm{td}, J=7.6,1.2 \mathrm{~Hz}, 1 \mathrm{H}), 7.69(\mathrm{td}, J$ $=7.5,1.0 \mathrm{~Hz}, 1 \mathrm{H}), 7.29-7.22(\mathrm{~m}, 2 \mathrm{H}), 7.16(\mathrm{~s}, 1 \mathrm{H}), 6.87-$ $6.76(\mathrm{~m}, 3 \mathrm{H}), 6.06(\mathrm{~d}, J=0.9 \mathrm{~Hz}, 1 \mathrm{H}), 6.00(\mathrm{~d}, J=0.8 \mathrm{~Hz}$, 1H), $5.04(\mathrm{~s}, 1 \mathrm{H}), 3.69(\mathrm{~s}, 3 \mathrm{H}) ;{ }^{13} \mathrm{C}$ NMR (DMSO-d 6,125 $\mathrm{MHz}) \delta: 176.8,176.6,156.9,155.9,145.7,143.9,141.7$, 136.3, 134.0, 130.3, 129.2, 129.2, 127.6, 127.4, 123.3, 116.0, 113.4, 112.8, 106.8, 100.7, 97.5, 54.0, 35.7; HRMS (ESI) calc. for $\mathrm{C}_{25} \mathrm{H}_{17} \mathrm{O}_{6}\left([\mathrm{M}+\mathrm{H}]^{+}\right)$: 413.1021. Found: 413.1001. 